\title{
Impact of Government Interventions on Corona Virus Transmission in Nigeria
}

\author{
Muhyideen Oloyede \\ Institute of Geoscience and Space Technology, Rivers State University, Port Harcourt, Nigeria
}

Abstract:- Many measures such as multi-sectoral National Coronavirus Preparedness Group and social interventions were instituted by Nigerian governments before and after the first case of COVID-19 was recorded on February 27, 2020. Impacts of these intervention measures on COVID-19 transmission were assessed within the first 82 days in Nigeria and in the first 38 days in Kano state. These approaches toward containing the spread of COVID-19 include nonpharmaceutical intervention measures, multi-sectoral Emergency Operations Centre (EOC) was activated at Level 3, expansion of labouratories, RRT deployment etc which resulted in the slow transmission trajectory and low COVID-19 burden and death burden on the people. The analysis of the COVID-19 data obtained between February 27 and May 20, 2020 (82 days period) showed that Nigeria recorded lower death burden of one (1) per million population compare with other African countries like South Africa with death burden of 6 death per million population each and other countries, death burden increases (> 1) as COVID-19 cases increases. Similarly, COVID-19 burden of Nigeria is 33 cases per million which is also very low compared to other African countries and other highly affected countries like US and UK. By 20th May 2020, 6,677 confirmed cases and 202 deaths and 1,860 recovered from COVID-19 have occurred in Nigeria. At day 82, the exponential growth rate calculated was 0.05 . The result of this study also provides epidemiological analysis of the first 40 days of COVID-19 outbreak in in the most populous state in Nigeria-Kano. Using this logistic model equation $[y=1.5 *(1.3) x]$ generated from the curve, a total of 31,158 infections was averted in Kano state by the federal and state government intervention measures and citizen level of compliances as well as additional effort of WHO official which altogether brought the total infections to 900 as against 32,058 infections predicted by logistic model. Simulation of the same model predicts total infections of $6,092,642$ by 9th of June more than half of state population in the absence of aforementioned interventions while by 11th of June 11,435,884 infections (state population). The results show COVID-19 positive cases are higher in the states with high population densities. Pearson productmoment correlation shows that strong positive association between COVID-19 cases and population densities $(r=0.869, p=0.000)$. Also, the difference between COVID-19 positive cases and population densities means is significant. Coefficient of determination is shows that $76 \%$ of the COVID-19 transmission could be attributed to population densities $(\mathrm{R} 2=0.76)$. In addition, there is a moderate positive association between COVID-19 cases and population densities $(r=0.645, p=0.000)$. Also, the difference between COVID-19 positive cases and population densities means is significant. The two associations are statistically significant at $99 \%$ confidence limit $(0.01$ level two tailed). As the COVID-19 cases and death from the pandemic are on the increase, strict compliance with measures to contain the spread of the disease such as social distancing, regular hygiene, wearing of face mask, restriction of movement and taking necessary precautions in all risk factors like in high people density areas etc need to be observed.

Keywords:- Africa; COVID-19; Nigeria; coronavirus; reproduction number; logistic model; non pharmaceutical interventions; Rapid Response Team (RRT).

\section{INTRODUCTION}

2019 novel corona virus which was officially named as COVID-19 is the causes of corona virus disease (WHO). The word virus comes from a Latin word meaning venom and describes a tiny, tiny agent that causes infectious disease. While the word corona means crown, coronavirus is a family of viruses that got its name from its appearance (crown). The scientists who in 1968 came up with the term coronavirus thought that, under a microscope, the virus they were looking at resembled a solar corona: the bright crown-like ring of gasses surrounding the sun that is visible during a solar eclipse according to Steinmetz, (2020) or a circle of light that can sometimes be seen around the moon at night as defined by Cambridge English Dictionary.

The corona virus disease emerged in Wuhan, China on 31 December, 2019 and spreads from there like wild fire within a short period of time to different parts of the world and was declared a global pandemic by the World Health Organization (WHO) on March 11, 2020 (WHO, 2020). As at $24^{\text {th }}$ of May, 2020, over 5,486,367 people were infected.

\section{$>$ Dangers of COVID-19}

Dangers /problems of COVID-19 are numerous as can be seen all over the globe manifesting in effects ranging from fear of getting infected with the pandemic diseases, loss of jobs/pay cut, suicide, death etc. According to Duffin, E. (2020), most major economies will lose at least 2.4 percent of the value their gross domestic product (GDP) over 2020 and global economic growth drop of 0.4 percent amounting to almost 3.5 trillion U.S. dollars in lost economic output as predicted earlier should/incase the virus become a global pandemic. As at May 24, 2020, over $5,486,367$ confirmed cases of infection and over 346,225 
people have died globally. Within 82 days of the outbreak of COVID-19 in Nigeria that is by $20^{\text {th }}$ May 2020, 6,677 confirmed cases and 202 deaths and 1,860 recovered from COVID-19 have occurred.

The situation in Kano provides an example of some of the challenges that might be faced elsewhere in Nigeria and the world (Campbell and Gavin 2020). Kano state is therefore used as a case study for this work. Between April 11, 2020 and May 20, 2020 (40 days period), a total of 848 (NCDC 847) confirmed cases, 121 discharged and 36 COVID-19 deaths were recorded in Nigeria.

Inspite of these numerous dangerous effects of COVID-19, many people still down play the problems of this disease. The perception of people of corona virus transmission in Kano like many other places is between real and virtual/unreal for which WHO Africa (2020) posited that-'Kano - From "COVID-19 does not exist", to COVID is not going to survive in Kano, to COVID is finished as soon as it gets here, Kano state residents got so comfortable and rebuffed Nigeria Center for Disease Control (NCDC) guidelines on COVID-19.'-until cases of infections recorded spread fast. The first case of COVID-19 was recorded on April 112020 and in about 3 weeks days over 300 persons were infected. As at $20^{\text {th }}$ of May, 2020, the state recorded 848 cases, 36 death and 121 recovered. Adding that, the state recorded highest daily infection of 92 cases on May 1 bringing the total cases to 311 .

Ewang (2020) reported hundreds more deaths than usual across communities in Kano State and there was fear that a major Covid-19 outbreak is underway. These deaths according to an independent survey conducted by staff at Kano's Yusuf Maitama Sule University, which examined the symptoms and demographic profile of patients, strongly suggests Covid-19. This and few other reports according to Amaza (2020) suggest the occurrence of community transmission as the reports on the cases show that-the pattern of the deaths reflects those of the global pandemic in terms of symptoms, incubation period, age group affected and other demographic characteristics. Ewang further stressed the need for authorities to act quickly to ensure accurate public health information is available and accessible to all.

Prior to the emergent of COVID-19 in Nigeria, the federal government of Nigeria set up a Coronavirus Preparedness Group to mitigate the impact of the virus if it eventually spreads to the country on 31 January 2020 (Martins 2020). Multi-sectoral Emergency Operations Centre (EOC) was activated at the highest emergency response level in Nigeria and deployment of COVID-19 starter packs to all-institutions and Federal Medical Centres. The government also carry out the expansion of labouratory network for COVID-19 across the 6 geopolitical zones and Deployed Rapid Response Team (RRT) to support response in all states with confirmed case(s) NCDC (2020). President Muhammadu Buhari established a Presidential Task Force for the control of the virus in the country (Daka and Agbakwuru 2020). Effective contact tracing starting from the first person to contact the virus as reported by Ifijeh $^{\mathrm{b}},(2020)$ that 60 persons who had contact with the index Italian patient were under isolation, 40 persons in Ogun State and 20 in Lagos State. This is followed by partial and total lock down of some states and imposition of nationwide curfew in March. In order to prevent or reduce person to person contact transmission of COVID-19, governments introduce and are enforcing social distancing, wearing of face mask, regular hygiene, closure of schools and market, certain restriction of movements. All these measures are effective in reducing transmission of COVID19 as reported by earlier work.

With all these measures in place and the lock down of this populous state on April 27,2020, Kano state was also assisted by world health organization (WHO) deployed a Rapid Response Team (RRT), trained and deployed additional 88 Local Government Facilitators (LGAFs) to support the ongoing COVID-19 response at the LGA level, to strengthen active case search, reporting and contact tracing, risk communication and infection prevention and control according to WHO Africa (2020).

\section{MATERIALS AND METHODS}

Daily data of COVID-19 positive cases were collected from Nigeria centre for disease control (NCDC), world health organization (WHO) daily situation reports and collated and published information in Wikipedia. These data were arranged in excel 2010 model and descriptive statistics was used to compare the minimum, maximum, mode and average. Graphs and other computations and simulations were conducted using excel 2010, MATLAB version 7.50 (2007b) and statistical package for the social sciences (SPSS) statistics version 20.

Reproduction number and doubling time were determined from the COVID-19 positive cases data from Feb27 to May 20, 2020. Also, transmission/infection progression was computed using the reproduction number and doubling time determined. The graph of daily infection cases, death and recovery were ploted against time in days in Nigeria from Feb27 to May 20, 2020.

As for Kano state, the graph of daily infection cases was plotted against time in days from April 11 to May 20, 2020. The logistic model equation $y=1.5^{*}(1.3)^{\mathrm{x}}$ was generated from the epidemic curve. This model equation generated from the graph was used to determine the number of positive cases averted by the non-pharmaceutical interventions.

Transmission progression table was developed through calculation for unabated or uncontrolled cases using the parameters such as reproduction number $(\mathrm{R})$ and doubling time estimated from the actual COVID-19 case data and those estimated in other documented researches and graph plotted using excel 2010. Pearson productmoment correlation was used to test for association and significant difference between the COVID-19 cases and population densities as well as between COVID-19 cases 
and population. The population densities and population are for different states in Nigeria with COVID-19 cases.

In Nigeria, within 82 days, between February 27, 2020 and May, 2020, a total of 6678 (NCDC 6,677) confirmed cases, 1,860 recovered and 202 COVID-19 deaths. In Kano state, between April 11, 2020 and May 20, 2020 (40 days period), a total of 848 (NCDC 847) confirmed cases, 121 discharged and 36 COVID-19 deaths were recorded in Nigeria.

It should however be noted that there is a difference of one case in the COVID-19 cases used in this work for Nigeria ie 6,678 as against 6,677 cases computed and reported by the NCDC and that used in this work for Kano state 848 as against 847 cases computed and reported by the NCDC. This is due to error in NCDC computation of the cumulative COVID-19 value in April 19 which was supposed to be 37 and they recorded 36 . There was zero case on that April 19 which means that the cumulative supposed to be equal to April 18 which was 37.Subsequently, the data trajectory proceeded with this minus 1 as April 20 with 23 case supposed to give cumulative of 60 instead of 59 recorded.

\section{RESULTS}

The result of the first 82 days COVID-19 data in Nigeria between February 27, 2020 and May, 2020, and the result of 40 days COVID-19 data in Kano state are presented in different graphs below.

As at May 20, 2020, 34 states and federal capital territory (FCT) have record of COVID-19 cases as shown in figure 1 map. Time series plot of daily infections, recovery and death counts figure 1 graph. Figure 2 Predictive model for The COVID-19 Infections for Nigeria. First 45 days of corona virus infection transmission Kano shown in figure 3 titled plot of COVID-19 cases against time (in days) in Kano state. Five days with new cases of infections in states with high and low population densities is explained in Figure 4 while Figure 5 is a Graphical description of COVID-19 positive cases and population densities against state population. COVID-19 transmission trajectory of computed (unabated) and real values are as described in table 1 and figure 6.

Figure 1 presents the cumulative number of confirmed cases, number recovered and number of death over time. The trend of incidence shows an exponential growth.

\section{A. Data Presentation and Analysis}

\section{Nigeria Situation}

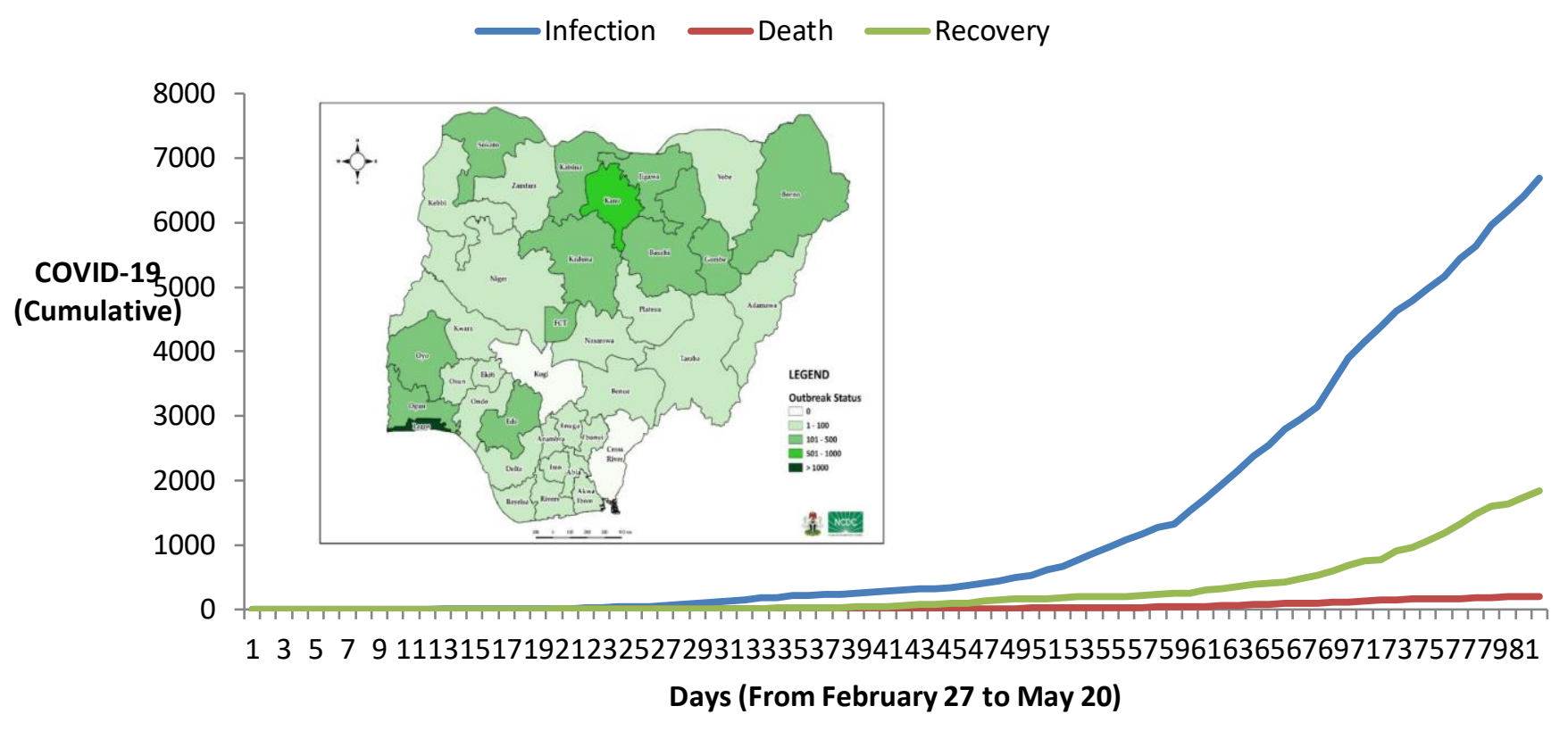

Fig 1:- Time Series Plot of Daily Infections, Recovery And Death Counts and Map of Nigeria Showing 34 States and FCT Affected by COVID-19 between February 27 and May 20, 2020.

Figure 1shows spread of COVID-19 disease in Nigeria between February 27, 2020 and May 20, 2020.

Infections and death curve is on the increase. Recovery is also increasing but not high enough to bring down the infections. 


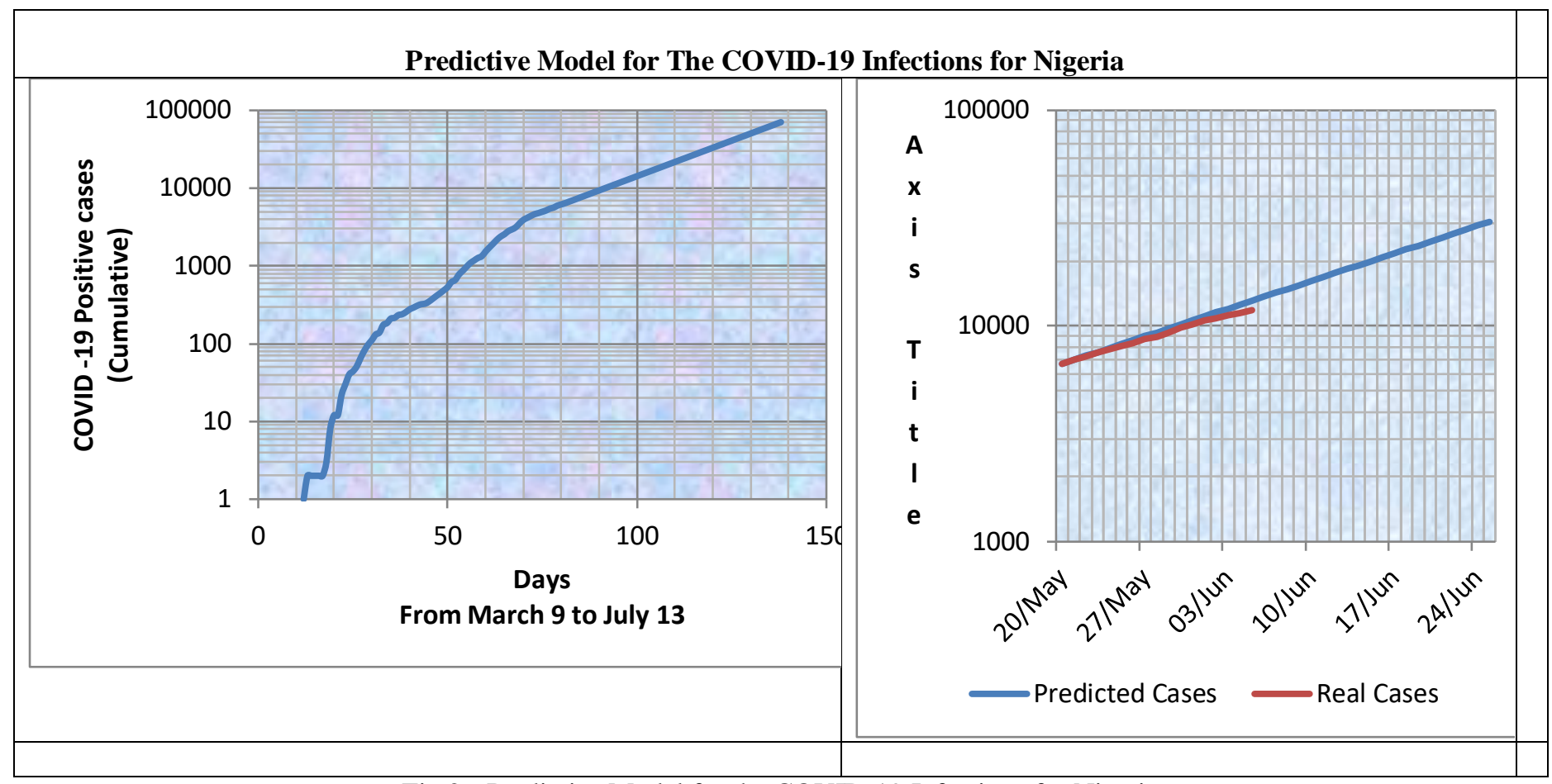

Fig 2:- Predictive Model for the COVID-19 Infections for Nigeria

\section{Kano case}

Kano recorded its first case on April 11 with 1 persons infected (NCDC, 2020). And since then the rate keeps increasing. On $27^{\text {th }}$ of April, Federal government ordered the lockdown of the state: strengthening the state government directives on the same matter. This synergy order of both the federal and state government changed the curve pattern from going towards the yellow line at the highest infection numbers (92) with cumulative infections of 311 persons $\left(19^{\text {th }}\right.$ day on the graph coinciding with $1^{\text {st }}$ of May) but instead the graph moved towards the blue line with the governments interventions. The yellow line showed total infection reaching 900 in less than 5 days (on $6^{\text {th }}$ May) the peak which was later reached in 19 days (on $20^{\text {th }}$ May) due to the level of compliance of the people of Kano state from my simulation.

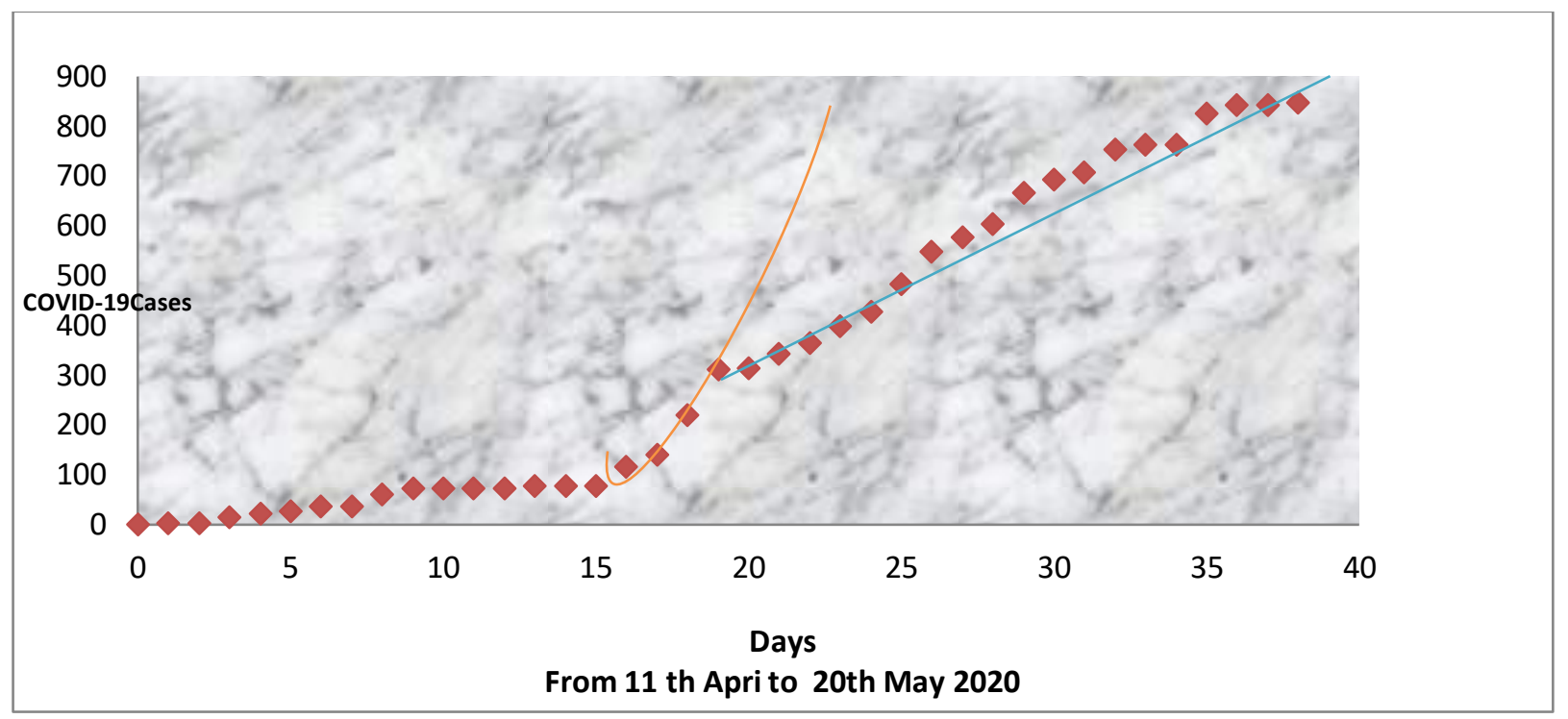

Fig 3:- Transmission of Covid-19 Infections in Kano State

Using the logistic model, the curve produced from day 19 with yellow line would have resulted in 32,058 infections (cumulative) by $20^{\text {th }}$ of May 2020 ie $38^{\text {th }}$ day in the graph as against 900 infections recorded. The difference of 31,158 infections was averted by the federal and state government intervention and citizen level of compliances well as additional effort of WHO official otherwise the total infections would have been 32,058 as obtained from logistic model equation $\left[y=1.5 *(1.3)^{x}\right]$ generated from the curve produced with yellow line. The model predict total infections of $6,092,642$ by $9^{\text {th }}$ of June more than half of state population in the absence of aforementioned interventions while by $11^{\text {th }}$ of June $11,435,884$ infections (state population). 
ISSN No:-2456-2165

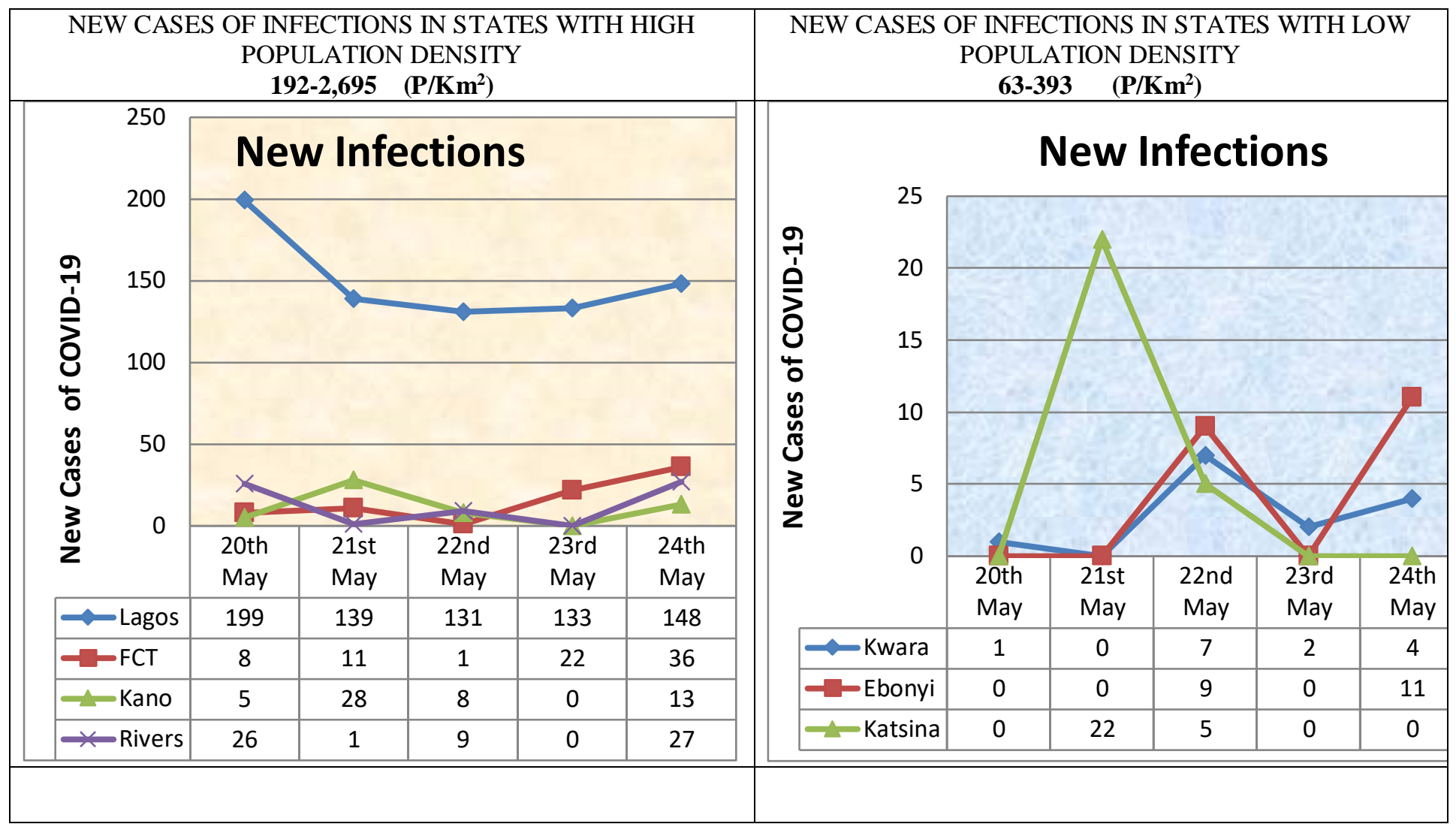

Fig 4:- New Cases of Infections in States with High and Low Population Densities

\section{- Infection and population Density}

COVID-19 positive cases are higher in the states with high population densities. Lagos has the highest population density of 2,695 and the highest number of COVID-19 cases while Kwara has the lowest population density of 63 persons per square kilometer and recorded low COVID-19 cases as contained in the figure 4 above.

Plot of COVID-19 Positive Cases/ Population Density against Nigerian State Population

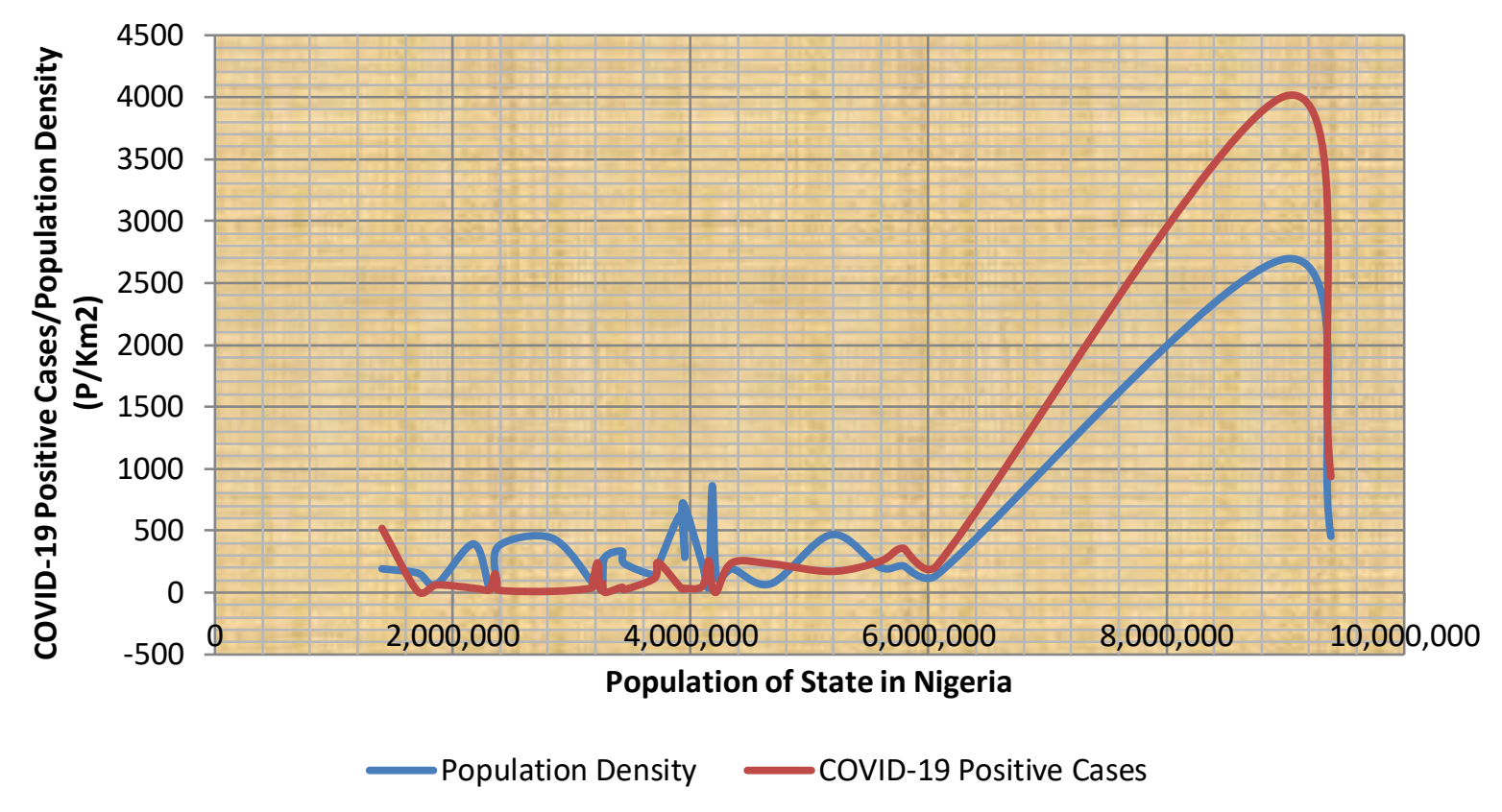

Fig 5:- Graph of COVID-19 Positive Cases and Population Densities against State Population 
Source of data: National Population Commission 2006, Landmass complied from NPC Report, 1991 and Field Reports,,MACOS Urban Management Consultants Database Management Profile. Lists of Nigerian State by Landmass and Population Density and NCDC (2020) COVID-19 Situation report of 27th of May 2020.

Figure 5 above shows the relation between COVID-19 positive cases and population densities of states in Nigeria as well as the relation between COVID-19 positive cases and population. COVID-19 increases with population density and the increases with the state population There was a strong positive association between COVID-19 cases and population densities $(\mathrm{r}=0.869, \mathrm{p}=0.000)$. Also, the difference between COVID-19 positive cases and population densities means is significant. Coefficient of determination is showing that $76 \%$ of the COVID-19 transmission could be attributed to population densities $\left(\mathrm{R}^{2}=0.76\right)$. There was a moderate positive association between COVID-19 cases and population densities ( $\mathrm{r}$
$=0.645, \mathrm{p}=0.000)$. Also, the difference between COVID19 positive cases and population densities means is significant. While there is strong positive association between COVID-19 cases and population densities, then there is moderate positive association between COVID-19 cases and population. The two associations are statistically significant at $99 \%$ confidence limit (0.01 level two tailed).

Two states with almost equal population but different population densities shows different infection cases at the same duration of time. Lagos and Kano states for instance in eight weeks of progressive transmission of the virus ie 1,761 cases (1,764 - 3) between March 17 and May 9 for Lagos state while 996 cases (997 - 1) between April 11 and June 6 for Kano state. High population density of Lagos state of 2,695 persons $/ \mathrm{Km}^{2}$ compare with relatively low population density of Kano state of 454 persons $/ \mathrm{Km}^{2}$ as a major factor. This high population density increases person to person contact rate which consequently results in high COVID-19 cases as reported above for Lagos state.

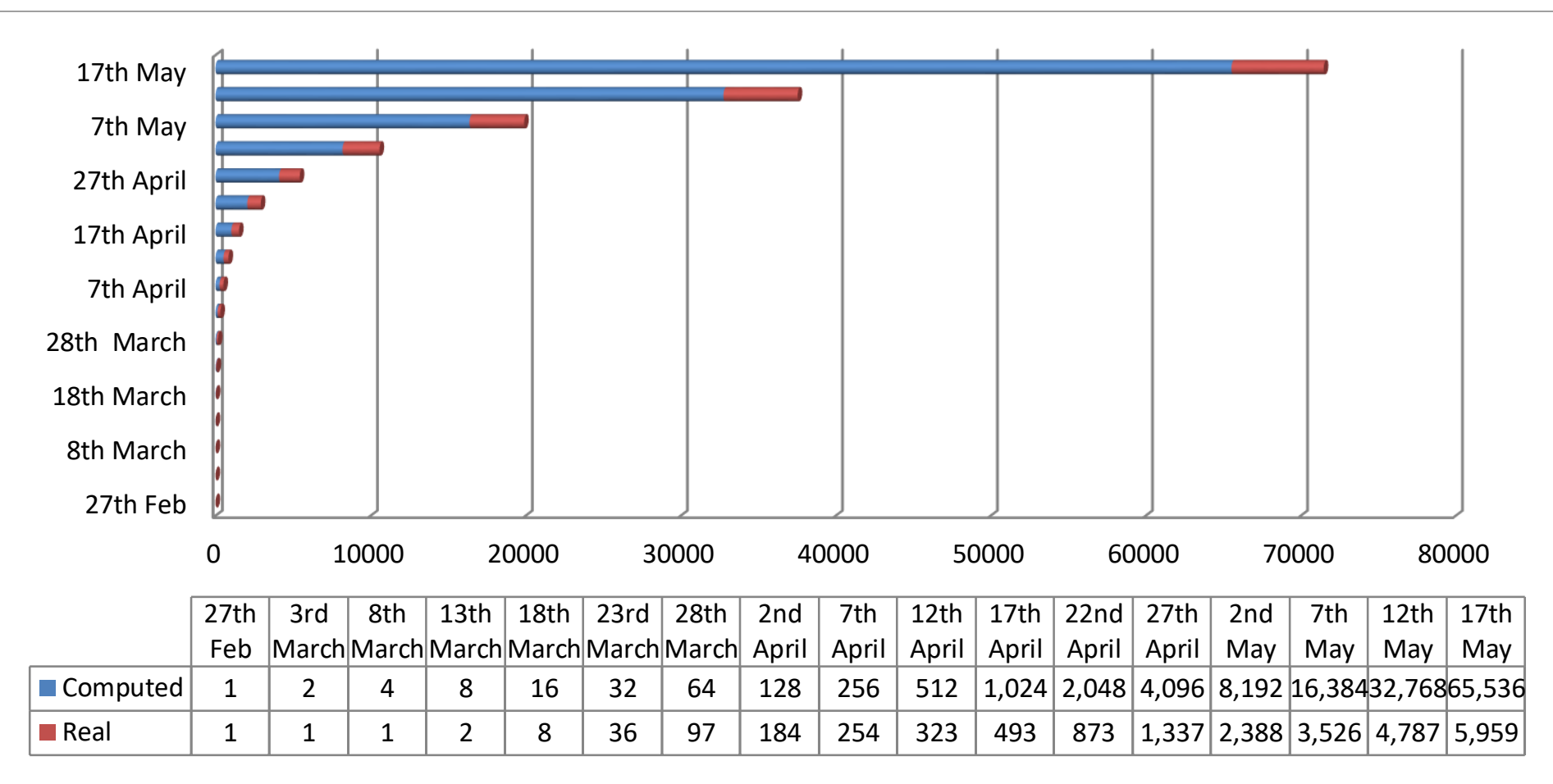

Fig 6:- COVID-19 Transmission Trajectory of Computed and Real Values

Figure 6 above compares the cumulative values of both the real/actual COVID-19 positive cases with computed unabated COVID-19 cases with time. The actual or real COVID-19 cases data were collected from Nigerian centre for disease control (NCDC) daily report and data from Wikipedia from February 27 when the first case was recorded. Also from this first person tested positive for COVID-19, transmission progression was developed through calculation for uncontrolled or unabated cases using the parameters such as reproduction number $(\mathrm{R})$ and doubling time estimated from the actual COVID-19 case data and those estimated in other documented researches.
Liu et al (2020) in their review work found that the estimated mean $R 0$ for COVID-19 was around 3.28, with a median of 2.79 and IQR of 1.16 , which is considerably higher than the WHO estimate at 1.95 due to the method used in their estimation. On the other hand, Adegboye et al, (2020) found the median reproduction number over the first 45 days study period was 2.71 . The reproduction number found in this study was 2.19 at May 20, 2020. Therefore, reproduction number of 2 was used for computing COVID-19 transmission progression Table 1. 
The basic reproduction number $(\mathrm{R})$ is used to measure the transmission potential of a disease. The reproduction number of 2 is used for computing the table below. Estimated doubling time from the first case of corona virus infections to May 20 ranges between 2 and 11 with 4 days doubling time appearing more than others. For computing the table below, doubling time of 5 days is used.

In the two progressions above that both started from just one COVID-19 case, the growth rate in computed values is far higher than the actual or real values. There is marginal difference between each pair of computed and real cases. In April 7, the difference is 2 (i.e 256-254), in April 17 is 531 , in May 12 is 27,981 etc.

\section{DISCUSSION}

Nigeria was one of the first countries to recognize the risk and start planning the response for COVID-19 culminating into the establishment of a multi-sectoral National Coronavirus Preparedness Group by Nigeria CDC on January 72020 , one week after China first reported the cases and three weeks before WHO declared the disease to be pandemic (Kapata et al, 2020). They further reported that the most populous African nation has also established diagnostic capacity for COVID-19 in many laboratories within the country and as well established a national team that meets daily to assess the risk coronavirus poses to the nation and review its response to it.

Adding that many states were locked down, imposition of curfew and non-pharmaceutical interventions among other measures were also put in place. Corroborating these, The two progressions shown in figure 6, the real COVID-19 progression was slower compare to the computed cases as supported by Adegboye et al (2020) who reported that the epidemic trajectory has been slow, in part, due to the public health interventions implemented in Nigeria which have reduced both local transmission and importation coupled with travel ban, closure of schools and restriction on movements.

The differences between each pair of real and computed cases increases with days. In May 17, the difference is 59,577 and in May 20 the difference is 143,885 etc. This model also predicted $180,822,630$ cases by June 21 and over 1 billion cases from July 21, 2020.This predicted COVID-19 epidemics is similar to the report of Wells et al (2020) who simulated a COVID-19 outbreak in DR Congo one of the most vulnerable African countries in the absence of interventions using assumed basic reproductive number of 2.72 and his estimation showed that there would be $76,213,155$ infections and 319,441 deaths in the absence of physical distancing.

Similarly, the result of analysis of Kano state cases showed that the difference of 31,158 infections was averted by the federal and state government intervention and citizen level of compliances well as additional effort of WHO official otherwise the total infections would have been 32,058 as obtained from logistic model equation $[y=$ $\left.1.5^{*}(1.3)^{\mathrm{x}}\right]$ generated from the curve produced with yellow line. The model predict total infections of $6,092,642$ by $9^{\text {th }}$ of June more than half of state population in the absence of aforementioned interventions while by $11^{\text {th }}$ of June $11,435,884$ infections (state population).

Results of analysis of 82 days epidemiology of COVID-19 showed that Nigeria has lower COVID-19 burden and death burden per million populations. As at May 20, 2020, Nigeria recorded a total of 202 COVID-19 deaths, with estimated population of 205.5 million recorded a total of 6,677 confirmed cases which is equivalent to one (1) death per million population. In comparism with other African countries, Nigeria has lower death burden per million population as the number of deaths per million population recorded by South Africa (59.2 million) with 18,003 cases and total of 339 deaths was 6 . This is far higher than that of Nigeria.

Generally, Nigeria has lower COVID-19 burden Adegboye et al (2020) and JHU,( 2020) which is reflected in the slow transmission trajectory and low COVID-19 burden and death burden on the people. The analysis of the COVID-19 data obtained between February 27 and May 20, 2020 (82 days period) showed that Nigeria recorded lower death burden of 1per million population compare with other African countries like South Africa with death burden of 6 deaths per million population each and other countries death burden increasingly greater than 1 as COVID-19 cases increases.

Similarly, COVID-19 burden of Nigeria is 33 cases per million which is also lower when compared to other African countries like South Africa with 18,003 cases having COVID-19 burden of 304 cases per million population and Ghana with 6,269 cases having COVID-19 burden 202 cases per million population. Apart from African countries, United State of America (329.3million) with 2,255,119 COVID-19 cases and 119,719 deaths has 6,848 COVID-19 burden and 364 death burden per million population. United Kingdom with relatively lower population compared with America (65.1million) with 304,580 COVID-19 cases and 42,674 death has 4,679 COVID-19 burden and 656 death burden per million population.

Low COVID-19 burden and death burden in Nigeria is supported by the earlier work of Adegboye et al, (2020) and the later report of JSU (2020). Early epidemiological studies of COVID-19 in the first 45 days showed that Nigeria COVID-19 burden was the least compared with other African countries. Assessing the case (per 100,000) during the first 45 days, the burden of COVID-19 is lowest in Nigeria (0.16) cases per 100,000 as of April 11, 2020) among African countries with the most cases (Adegboye et al, 2020). They further reported that the disease spread occurred more slowly in Nigeria within the first 45 days and that Nigeria COVID-19 burden was lower when compared with some of the most affected countries outside of Africa like US and Italy with COVID-19 burden of 
60.89 and 244.00 cases per 100,000, respectively, as at April 11, 2020.

Later epidemiological report of Johns Hopkins University of Medicine (JSU) showed that the death burden per million population was also lower when compared with other affected African countries. Nigeria has lower death burden per million population when compared to the 7 deaths per million population recorded by South Africa (59.2 million) with 21,343 cases and total of 407 deaths and Egypt (102.1 million) with 16,513 cases and total of 808 deaths (JSU, 2020).

The results show COVID-19 positive cases are higher in the states with high population densities. This is as shown in state like Lagos, Kano, Rivers, with population densities (192 - 2,695 p/KM ${ }^{2}$ ) with daily infections as high as 199 cases per day as compare with states like Kwara, Ebonyi having low population densities (63-393 p/KM ${ }^{2}$ ) with high infection cases of 22 as shown in figure 4 above.

The effect of high population densities places is also corroborated by the report of the findings of US CDC which holds that the coronavirus primarily spreads from person to person and not easily from a contaminated surface. According to Guarino and Achenbach (2020) in US CDC who also classified high people density places as high risk factor.

For a healthy person to be successfully infected, the virus needs a dose of approximately 1000 viral particles (vp). While breath and speaking produce approximately 20 and 200vp/minute, sneeze and cough produce/pour out approximately 200 million vp according to USA CDC (2020). It therefore show the danger of COVID-19 transmission to many people in high density areas as did happen when superspreader -an index case-gave it to 43 people in Italy (Christakis, 2020), 77persons infected in a Cambridge biotech company Biogen meeting held in Boston Marriott Long Wharf, hotel, a British man spread the virus to 11 people at a French ski resort after he had visited Singapore for a conference etc. US CDC (2020) also regarded gatherings in enclosed spaces like offices, religious places, cinema halls or theatres to be of high risk and that these findings need to be applied by people to manage the situation in the best manner possible.

In the two progressions above (figure 6), both started from just one COVID-19 case but the growth rate in computed values was far higher than the actual or real values. The difference between the computed and real in April 7 is 2 (256-254), in April 17 is 531, in May 12 is 27,981 etc. The relatively low daily values of the real COVID-19 cases according to Adegboye (2020) was due to series of immediate interventions that were put in place by the government of Nigeria in response to COVID-19. The interventions which include international travel ban imposed countries on March 20, 2020, early closure of schools, restriction on movements within and outside of major cities and its enforcement etc. To this end, Ebenso (2020) and NCDC (2020) added that the epidemic trajectory has been slow, in part, due to the public health interventions implemented in Nigeria which have reduced both local transmission and importation.

These differences between the real and computed cases are the estimated cases averted thought largely to be due to factors including non-pharmaceutical interventions, other measures put in place by governments, etc.

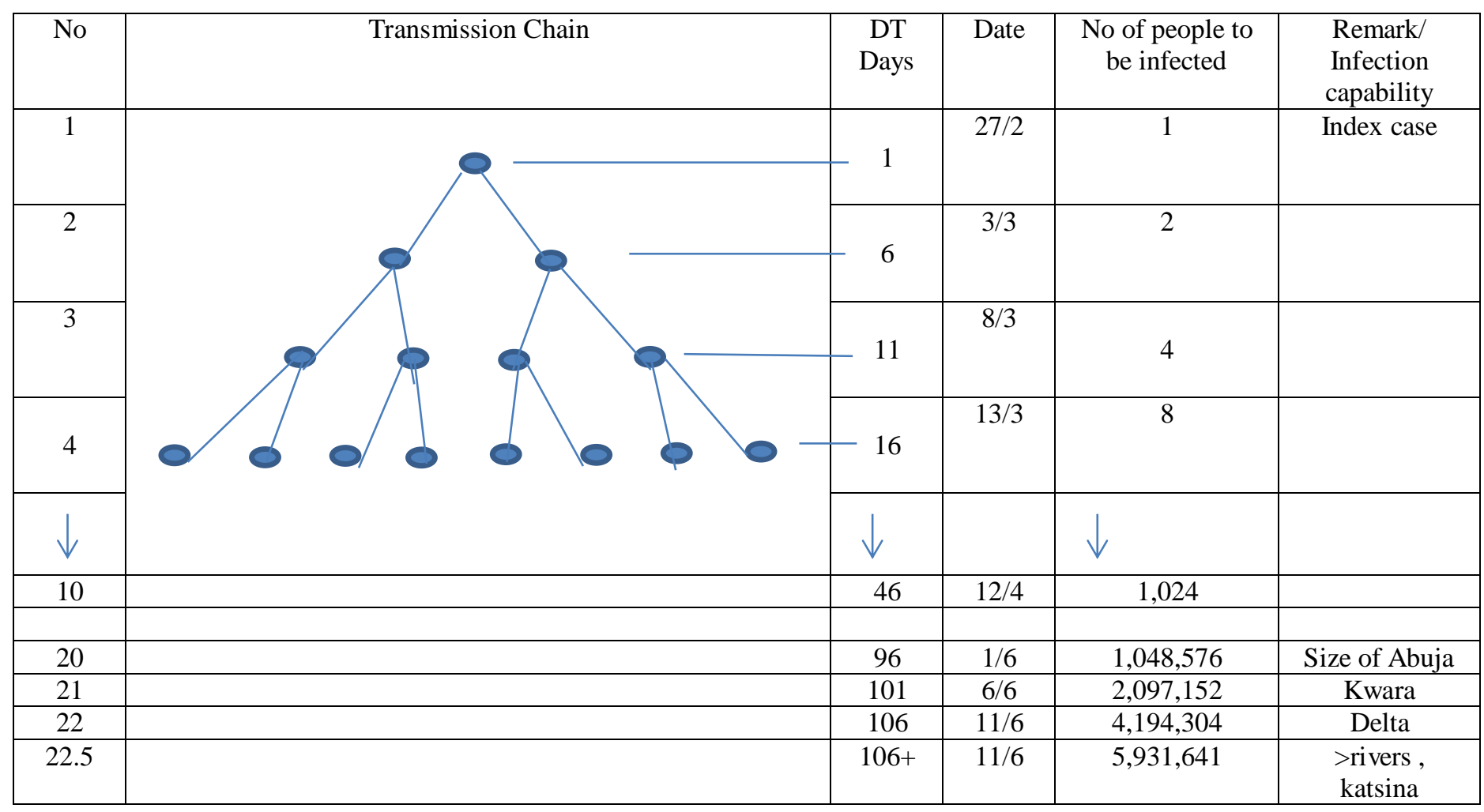


ISSN No:-2456-2165

\begin{tabular}{|c|c|c|c|c|c|}
\hline & & & & & \\
\hline 23.2 & & $111+$ & $16 / 6$ & $9,635,980$ & Lagos, kano \\
\hline & & & & & \\
\hline 24.43 & \multicolumn{7}{|c|}{$116+$} & $21 / 6$ & $180,822,630$ & Nigeria pop \\
\hline 30 & IF NIGERIA IS TAKEN AS THE EPICENTER OF COVID-19 & \\
\hline 31 & & 146 & $21 / 7$ & $1,073,741,824$ & \\
\hline 32.71 & 151 & $26 / 7$ & $2,147,483,648$ & $\begin{array}{c}\text { >pop of China, } \\
\text { India }\end{array}$ \\
\hline & & $156+$ & $31 / 7$ & $7,025,725,186$ & World pop \\
\hline 33 & & & & & \\
\hline
\end{tabular}

Parameters used are Reproduction number $(\mathrm{R})=2$ and Doubling time $=5$ days

Table 1:- Unabated COVID-19 Transmission Trajectory

Unabated or uncontrolled disease transmission when there is no intervention. The reproduction of 2 estimated in this work and other researches as mentioned above is used for computing the table below. Estimated doubling time from the first case of corona virus infections to $20^{\text {th }}$ May ranges between 2 and 11 with 4 days doubling time appearing more than others. For computing the table below, doubling time of 5 days is used.

\section{CONCLUSION AND RECOMMENDATION}

Compliances with non-pharmaceutical intervention and other measures has averted lot of COVID-19 infection cases in Nigeria. Not only does it averted about 31,158 cases in Kano state alone but also brought down till date the number of daily cases from the highest infection of 92 (cumulative 311) recorded since April 11 when the first case was reported. The results of this studies show rise in the daily COVID-19 cases therefore strict compliance to all these aforementioned measures is highly recommended in order to flatten the curve. Government at all levels need to ensure strict compliance of the people especially in places or states with high population densities to forestall or prevent the occurrence of second surge/wave of the transmission as it happened in 1918 Spanish flu when one Albert Gitchell (index case) according to Taubenberger and Morens (2006) was infected in early March 1918 and transmission went through second and third waves until 1/3 (approximately 500 million) of the world population infected. Non-compliance with nonpharmacetical intervention measures like non observing quarantine, non-reporting the infection etc were reasons adduced for this historic pandemic that claimed the lives of over 50 million people.

\section{REFERENCES}

[1]. Adegboye, O. A., Adekunle, A. I. and Ezra Gayawan (2020) Novel Coronavirus in Nigeria: Epidemiological analysis of the first 45 days of the pandemic. medRxiv preprint doi: https://doi.org/10.1101/2020.04.14.20064949.

[2]. Agbakwuru, Johnbosco (9 March 2020). "Buhari sets up 12 member Task Force to control Coronavirus". Vanguard Newspaper. Retrieved 11 March 2020.

[3]. Amaza, M (2020) Nigerians fear a Covid-19 catastrophe is unfolding in Kano. Quartz Africa. https://qz.com/africa/1853926/nigerians-fear-a-covid19-catastrophe-is-unfolding-in-kano/amp/

[4]. Campbell, J. and Gavin, M (2020) Track Political and Security Developments across Sub-Saharan Africa. https://www.cfr.org/blog/how-nigeria-hasresponded-covid-19-so-far

[5]. Daka, FTerhemba (10 March 2020). "Buhari names task force on coronavirus". The Guardian Newspaper. Retrieved 11 March 2020.

[6]. Duffin, E (2020) Impact of the coronavirus pandemic on the global economy - Statistics \& Facts. https://www.statista.com/topics/6139/covid-19impact-on-the-global-economy/

[7]. Ebenso B, Otu A. Can Nigeria contain the COVID-19 outbreak using lessons from recent epidemics? The Lancet Global health 2020.

[8]. Cambridge English Dictionary. https://dictionary.cambridge.org/dictionary/english/co rona

[9]. Ewang, A (2020) Fears of Covid-19 Outbreak in Nigeria's Kano State. Authorities Need to Ensure Public Health Information Available to All. Researcher, Africa Division

[10]. Guarino, B and Achenbach, J (2020) The coronavirus primarily spreads from person to person and not easily from a contaminated surface from US Centers for Disease Control and Prevention, "How COVID-19 Spreads"

https://www.washingtonpost.com/health/2020/05/21/v irus-does-not-spread-easily-contaminated-surfaces-oranimals-revised-cdc-website-states/

[11]. Ifijeh ${ }^{\mathrm{a}}$, M. (2020). "FG Sets up Coronavirus Preparedness Group". This Day Newspaper. Retrieved 18 May, 2020.

[12]. Ifijeh ${ }^{\mathrm{b}}$, M. (2020). "Coronavirus Outbreak: Roundthe-clock Updates". This Day Newspaper. Retrieved 18 May 2020.

[13]. JHU, (2020) Johns Hopkins University of Medicine

[14]. Kapata, N., Tajudeen, R., Chanda, P and Mwaba, P. (2020) Is Africa prepared for tackling the COVID-19 (SARS-CoV-2) epidemic. Lessons from past outbreaks, ongoing pan-African public health efforts, and implications for the future. in International Journal of Infectious Diseases DOI: 10.1016/j.ijid.2020.02.049 
[15]. Liu, Y., Gayle, A. A., Wilder-Smith, A. and Rockl, J. (2020) The reproductive number of COVID-19 is higher compared to SARS coronavirus. Journal of Travel Medicine, 2020, 1-4 doi: 10.1093/jtm/taaa021.

[16]. NCDC, (2020) Nigeria Centre for Disease Control. COVID-19 Outbreak in Nigeria Situation Report. Abuja, Nigeria.

[17]. Steinmetz, K. (2020). Coronavirus-glossarydefinitions https://time.com/5798684/coronavirusglossary-definitions

[18]. Taubenberger, J. K and Morens, D. M. (2006)1918 Influenza: the Mother of All Pandemics Emerging Infectious Diseases • www.cdc.gov/eid • Vol. 12, No. 1 doi: $10.3201 /$ eid1201.050979

[19]. Warigon, C (2020)

WHO trains additional personnel to support COVID-19 response in Kano state | WHO | Regional Office for Africa" https://www.afro.who.int/news/who-trainsadditional-personnel-support-covid-19-response-kanostate. e-mail: warigonc@who.int

[20]. Wells, C. R., Stearns, J. K., Lutumba, P and Galvani, A. P (2020) COVID-19 on the African continent DOI:https://doi.org/10.1016/S14733099(20)30374-1. 